\title{
INTERACTION AMONG EXCHANGE RATE, INFLATION RATE, EXPORT AND IMPORT IN NIGERIA USING VECTOR AUTOREGRESSIVE (VAR) MODELS
}

\author{
${ }^{1}$ Uyodhu, Amekauma Victor-Edema \& ${ }^{2}$ Wiri, Leneenadogo \\ ${ }^{2}$ Department of Mathematics/Statistics \\ Ignatius Ajuru University of Education, \\ Port Harcourt, Nigeria \\ ${ }^{2}$ Rivers State Ministry of Education, \\ Port Harcourt Nigeria. \\ Corresponding Author Email: uyodhu.victor-edema@iaue.edu.ng
}

\begin{abstract}
This study examined the inter-relationship among exchange rate, inflation rate, exports and imports in Nigeria by applying the vector autoregressive model (VAR). The time plot of all the variables showcased irregular movements whereas they test for stationarity at constant, constant and linear trend all indicated stationarity of all variables at co-integration of order one I(1). The lag selection process revealed the lag length of one (1), was sufficient for the model based on the Schwarz information criterion. The stability test disclosed that the VAR model was stable as all the values of the characteristic polynomial are less than one. The trace test and max Eigenvalue result displayed co-integration among all the variables. The vector autoregressive model estimate indicated that export is significantly affected by import at lag one and the combined lag of each variable significantly affected itself. The impulse response function disclosed that all variable was affected by their shock positively and while negatively affecting one another. However, long-run stability existed among the study variables such as exchange rate, inflation rate, export and import. The steady-state condition can be reached between exports and import in Nigeria. The study finally recommends that the exportation of goods should be improved through the purchase of enhanced skill and means of manufacture; this will, in turn, decrease the request for the importation of goods in Nigeria.
\end{abstract}

Keywords: Interrelationship, Co-integration, Impulse Function, Vector Autoregressive, variance decomposition, Granger causality.

\section{INTRODUCTION}

Most economy watchers agree that import, inflation rate, export, and exchange rates are the important variables of the macroeconomic pillars of any countries. Taken together, these variables can be said to occupy the heart of the economy as the macro-economic indicators, giving signals regarding the macro-economic performance of the country. In practices, they 
stand as the basic item of an economic system, playing a serious role in determining the influencing real and minor economy (Bderezak \& Samet, 2016). The possible existence of the long run inter-relationship among the series, always obtains significant attention from a wide range of society's attention, ranging from policymakers, academics, economists, investors, companies, households etc. however, to understand the link between them, it's the importance's to establishes a basis for setting good macro-economic programme management (Jarita, 2008)

Nigeria likes other countries of the world, engaged in trade with other countries in the world. Nigeria exports agricultural products such as palm produce, rubber, cocoa etc, import machines, automobile etc. Generally, trade is an instrument to reduce the rate of inflation in any countries in the world

Tuaneh \& wiri 2019). Vector autoregressive models are extensively used to provide a practical estimate to multiple time series process. Jarita (2008) studied the association between the exchange rate, money supply, prices of import and prices of export. The result from the vector error correction model disclosed that exchange rate shock is significant after the fluctuation of import prices. Oluyemi and Essi (2017), survey the effect of exchange rate on import and export, using the vector autoregressive model. Their result indicated that a lag length of order 2 is adequate for the models and exchange rates to have a positive and minor effect on imports. Whereas, it has a negative and unimportant effect on exports at lag 1 but the positive and irrelevant effect at the lag length of order 2. Exports were also found to affect exchange rates negatively while imports affect exchange rates positively. The theoretical and analytical methods of the interrelationship between exchange rate inflation, import and export sequence are highlighted in this report. The researchers want to know the following things: the study area's long-term interrelationship between imports, exports, inflation, and exchange rates What sorts of empirical connections do they have?

The study aims to use a vector autoregressive (var) model to assess the interrelationship between the exchange rate, inflation rate, and import and export duties in Nigeria. The rest of the research is structured as follows: The literature and theoretical aspects of the relationship among exchange rate, inflation, import and export duties, as well as their empirical aspects, are discussed in the following pages. The other section organizes and discusses the study's econometric procedures and results in prediction.

\section{LITERATURE REVIEW}

Jarita (2008) investigate the relationship between the exchange rate, money supply, import and export prices. The findings revealed that after the fluctuation of import prices, exchange rate shock is important. Wiri \& Tuaneh (2019). The relationship between economist variables was modelled using a vector autoregressive model. According to the research, the exchange rate is Granger as a result of the market, oil sales, and government spending. The effect of the exchange rate on Romania's inflation rate was determined using a vector autoregressive model. According to the findings, a $1 \%$ rise in the exchange rate triggers a 0.36 per cent change in the producer price index-based inflation rate. 
Ukwuoma Ukwuoma Ukwuoma (2019) The var model is used to determine if there is a longrun or short-run relationship between the variables in the studies. His findings revealed that there is no statistically significant association between GDP, exchange rate, and oil export.

Oluyemi and Essi (2017) Using a vector autoregressive model, the study investigates the impact of exchange rates on imports and exports. The lag length selection criteria show that a lag of 2 is appropriate for the model based on the Schwarz knowledge criterion, according to their findings. The results of the Vector autoregressive model indicate that exchange rates have a positive and insignificant impact on imports, but a negative and insignificant effect on exports at lag 1, but a positive and insignificant effect at lag 2. Exports were also discovered to hurt exchange rates, while imports have a positive impact. Exchange rates reacted positively to imports and negatively to exports, according to the impulse response function's findings.

Granvile et al. (2001) looked at the multivariate time series model, which aims to solve the problem of having a good representation of the structure as well as effective parameterization. They used the low-order vector autoregressive model, which employs conditional independence graphs to find a sparse structural autoregressive presentation. The discovered structure exposes the critical function of the two-year rate series and highlights heteroscedasticity sources. When the series is of moderate duration, vector autoregressive models of high order are commonly used to provide an empirical approximation to multiple time series structure, but a large number of parameters in these models limits the potential maximum lag.

Tuaneh (2018). Examine the interdependence of macroeconomic variables and how they respond to shocks. On the sequence of inflation, exchange rate, and crude oil rates, the approach used was the Unrestricted Vector Autoregressive model. There is no co-integration among the study variables, according to the interactions and investigation of the pattern of Granger causality. A stable VAR model was revealed by the inverse root of the AR characteristic polynomial. The lag length of 1 was chosen by all lag length selection criteria. The post estimation study revealed that the VAR model was multivariate normal and the residual was homoscedastic, according to their findings.

Bderezak and Samet (2016) investigated the relationship between inflation and the exchange rate in Turkey, using the ordinary least square estimator and a simple generalized autoregressive conditional heteroskedasticity $(\mathrm{GARCH})$ model to evaluate the relationship. The regression model's findings indicate that purchasing power parity does not occur in Turkey. The presence of ARCH and GARCH in the relationship, on the other hand, suggests that the deviations from PPP are not spontaneous and follow a pattern. According to their findings, such variables as transaction costs in Turkey may be contributing to the deviation in purchasing power parity.

\section{METHOD OF SOLUTION}

The vector autoregressive model is an extension of the autoregressive model (AR) for modelling a multivariate time series. This model is flexible in modelling a multiple and multidimensional system. It is used to describing the performance of financial and economic time 
series data, analysing the dynamic impart of random error on the system. [10]. Mathematically, the Vector autoregressive model of order $p$ var $(p)$ is represented as follow

$$
\begin{aligned}
& \left(\begin{array}{c}
Y_{1 t} \\
Y_{2 t} \\
: \\
\cdot \\
Y_{m p}
\end{array}\right)=\left(\begin{array}{c}
c_{1} \\
c_{2} \\
\cdot \\
\cdot \\
\cdot c_{m}
\end{array}\right)+\left(\begin{array}{ccccc}
\gamma_{i, 11} & \gamma_{i 12} & \cdot & \cdot & \gamma_{i, 1 m} \\
\gamma_{i, 21} & \gamma_{i, 22} & \cdot & \cdot & \gamma_{i, 2 m} \\
\cdot & \cdot & \cdot & \cdot & \cdot \\
\cdot & \cdot & \cdot & \cdot & \cdot \\
\gamma_{i, m 1} & \gamma_{i, m 2} & \cdot & \cdot & \gamma_{i, m m}
\end{array}\right)\left(\begin{array}{c}
Y_{1, t-1} \\
Y_{2, t-1} \\
\cdot \\
Y_{m, t-1}
\end{array}\right)+\cdot \cdot \cdot \cdot+ \\
& \left(\begin{array}{ccccc}
\gamma_{i, 11} & \gamma_{i 12} & \cdot & \cdot & \gamma_{i, 1 m} \\
\gamma_{i, 21} & \gamma_{i, 22} & \cdot & \cdot & \gamma_{i, 2 m} \\
\cdot & \cdot & \cdot & \cdot & \cdot \\
\gamma_{i, m 1} & \gamma_{i, m 2} & \cdot & \cdot & \gamma_{i, m m}
\end{array}\right)\left(\begin{array}{c}
Y_{1 . t-p} \\
Y_{2, t-p} \\
\cdot \\
\cdot \\
Y_{m, t-p}
\end{array}\right)+\left(\begin{array}{c}
\varepsilon_{1 t} \\
\varepsilon_{2 t} \\
\cdot \\
\cdot \\
\cdot \\
\varepsilon_{m t}
\end{array}\right) \\
& Y_{t}=q_{0}+q_{1} z_{t-1}+\ldots \ldots \ldots \ldots .+q_{p} z_{t-p}+\varepsilon_{i} \\
& (\mathrm{x} \times 1)=(\mathrm{x} \times 1)+(\mathrm{x} \times \mathrm{x})(\mathrm{x} \times 1)+\ldots \ldots \ldots . .+(\mathrm{x} \times \mathrm{x})(\mathrm{x} \times 1)+(\mathrm{x} \times 1)
\end{aligned}
$$

The model is reduced to an Autoregressive model AR(p) of order p. (Box \& Jenkins, 1976). Equation (2.2) is called unstructured VAR (UVAR). (Enders, 1995).

$$
\theta(z)=1-\theta_{l} z-\theta_{2} z^{2}-\ldots \ldots \ldots \ldots \ldots-\theta_{p} z^{p}
$$

This is the characteristics polynomial of a vector autoregressive model of order $\mathrm{p}$ and the model is stable if the characteristics polynomial lie out the unit circle. Some assumption in the VAR model is that the error follows a multivariate white noise,

$\epsilon\left(\varepsilon_{i}\right)=0, \epsilon\left(\varepsilon_{i}^{2}\right)=\operatorname{var}\left(\varepsilon_{i}\right), \epsilon\left(\varepsilon_{i} \varepsilon_{j}\right)=\operatorname{cover}\left(\varepsilon_{i} \varepsilon_{j}\right) \neq 0$

The parameter in the models must contain certain restrictions for the vector autoregressive model to be stationary. The process is similar to the AR model case but in vector representation. It required the roots of characteristics polynomial are

$$
\left|1-\theta_{l} \mathrm{z}-\theta_{2} z^{2}-\cdots \ldots \ldots \ldots-\theta_{p} z^{p}\right|=0
$$

lie outside the unit circle. ( Chatfield,1984) 


\subsection{Lag length Selection Technique}

The method of selection of lag length $\mathrm{p}$ is base on the minimize the information criteria. The vector autoregressive of order $(p)$ model can be estimated using model selection criteria. The Schwarz information criterion is used for the selection is given by;

$\mathrm{SIC}=\ln \left|\Sigma_{r}\right|+\frac{\operatorname{InT} T}{T} \mathrm{M} K^{2}$

where;

$\mathrm{T}$ is the number of observations (after accounting for lags 2), $\mathrm{M}$ is the number of parameters

$\ln \left|\Sigma_{r}\right|$ is the $\log$ of the determinant of the covariance matrix of error of the restricted system. In each case, $\mathrm{M} K^{2}$ is the number of VAR parameter in a model with order $\mathrm{M}$.

\subsection{Test for Stationarity}

The study adopts the (ADF) and the correlogram to test for stationarity in the variables of the study.

$\Delta y_{t}=b_{10}+b_{11} y_{t-1} \boldsymbol{b}_{1 i} \sum_{i=1}^{p} \gamma_{i} \Delta y_{t-i}+\varepsilon_{t 1}$

where

$y_{t}=\Gamma\left(E X C_{t} I N F_{t}, I M P_{t} E X P_{t}\right)$

The (ADF) unit root test assumption the series must be $\mathrm{I}(\mathrm{d})$

\subsection{Granger Causality}

Granger (1969) was the first to testing for the direction of causality. Suppose we have two-time series variable $x_{t}$ and $y_{t}$ then we say that $x_{t}$ Granger causes $y_{t}$ if

$\mathrm{E}\left(y_{t} / y_{t-1,}, \ldots \ldots\right) \neq \mathrm{E}\left(y_{t} / y_{t-1}, y_{t-2}, \ldots x_{t-1}, x_{t-2} \ldots\right)$

\subsection{Impulse Response}

The response function links the result of a past shock to the current and future shock of the value of the endogenous variable. A shock on any variable not only affect another variable directly but also transferred to all of the other variables through the dynamic structure of the model (Tuaneh, \& Wiri, 2019).

\subsection{Co-integration test}

Regressing two or more non-stationary series may result in spurious regression. However, if the series is co-integrated spurious regression no longer exist. Two or more non-stationary 
series may possess the characteristic that a linear mixture of them is stationary $\mathrm{I}(0)$. If the property holds, then the series are co-integrated. Two co-integrated series will not drift too far from each other over the same time. Co-integration suggests that the analysis of short-run dynamics is often done by first eliminating the trend in the variable usually by differencing (Johansen, (1988).

\subsection{MODEL SPECIFICATION}

This study adopts a vector autoregressive model to analyse the inter-relationship among the exchange rate, inflation rate, export and import duties in Nigeria.

$$
\begin{aligned}
& \left(\begin{array}{l}
E X C_{t} \\
I N F_{t} \\
I M P_{t} \\
E X P_{t}
\end{array}\right)=\left(\begin{array}{l}
C_{1} \\
C_{2} \\
C_{3} \\
C_{4}
\end{array}\right)+\left(\begin{array}{llll}
\gamma_{11} & \gamma_{12} & \gamma_{13} & \gamma_{14} \\
\gamma_{21} & \gamma_{22} & \gamma_{23} & \gamma_{24} \\
\gamma_{31} & \gamma_{32} & \gamma_{33} & \gamma_{34} \\
\gamma_{41} & \gamma_{42} & \gamma_{43} & \gamma_{44}
\end{array}\right)\left(\begin{array}{l}
E X C_{t-1} \\
I N F_{t-1} \\
I M P_{t-1} \\
E X P_{t-1}
\end{array}\right)+\cdot \cdot \cdot+\left(\begin{array}{llll}
\gamma_{11} & \gamma_{12} & \gamma_{13} & \gamma_{14} \\
\gamma_{21} & \gamma_{22} & \gamma_{23} & \gamma_{24} \\
\gamma_{31} & \gamma_{32} & \gamma_{33} & \gamma_{34} \\
\gamma_{41} & \gamma_{42} & \gamma_{43} & \gamma_{44}
\end{array}\right) \\
& \left(\begin{array}{l}
E X C_{t-p} \\
I N F_{t-p} \\
I M P_{t-p} \\
E X P_{t-p}
\end{array}\right)+\left(\begin{array}{l}
\varepsilon_{1} \\
\varepsilon_{2} \\
\varepsilon_{3} \\
\varepsilon_{4}
\end{array}\right)
\end{aligned}
$$

The model is reduced to an Autoregressive model AR(4) of order 4.

$Y_{t}=b_{i}+\sum_{i=1}^{4} b_{i i} y_{t-i}+\varepsilon_{i}$

Where $Y_{t}$ is a $(4 \times 1)$ matrix of the endogenous variable, considered as the exchange rate. The inflation rate, import and export. $b_{i}$ is a fixed co-efficient matrix of $(4 \times 1)$ of intercept, $b_{i i}$ is $(4 \times 4)$ matrix containing the estimating parameter, $y_{t-i}$ is $(4 \times 1)$ matrix of the variable and $\varepsilon_{i}$ is the $(4 \times 1)$ matrix od dimensional white noise terms (Enders, 1995).

\section{EMPIRICAL RESULT AND DISCUSSION}

\subsection{Data Properties:}

The data used in the study was gotten from the Central Bank of Nigeria Web site. The time plot of the original series of the exchange rate, inflation rate, export and import without transformation is shown in figures (1-4). To remove the trend we take the first difference I(1) of data and the residuals plot is shown in figure (5) 


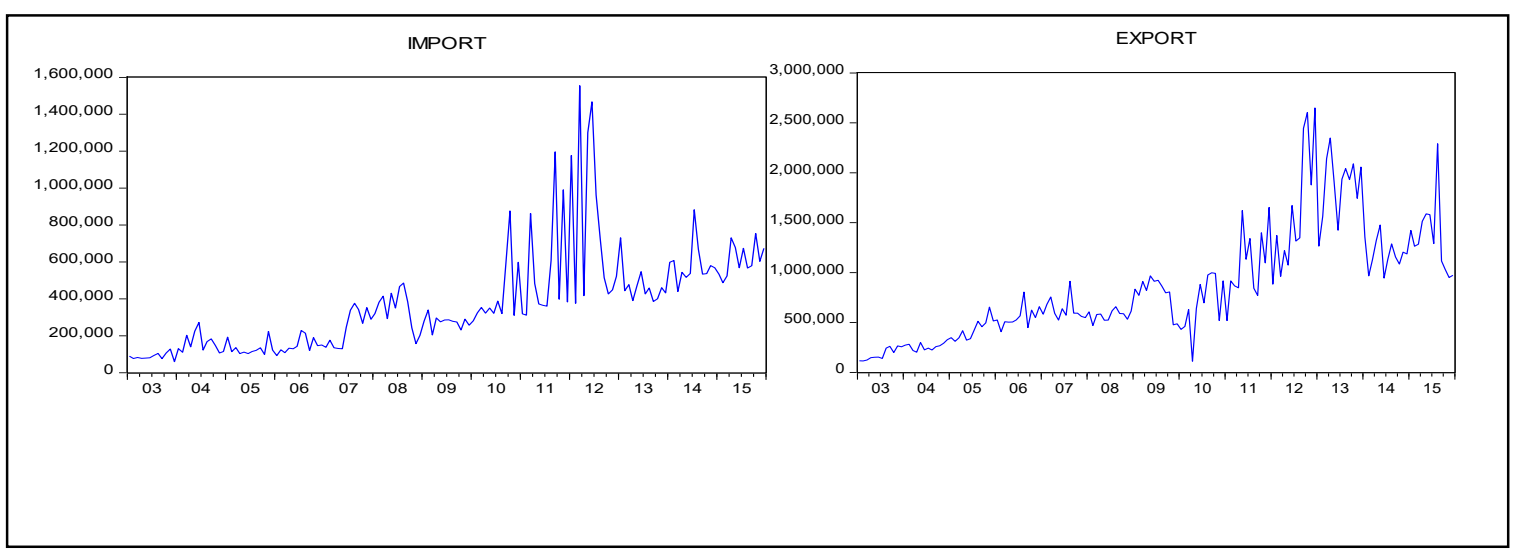

Figure (1) Time plot of Import

Figure (2) Time plot of Export

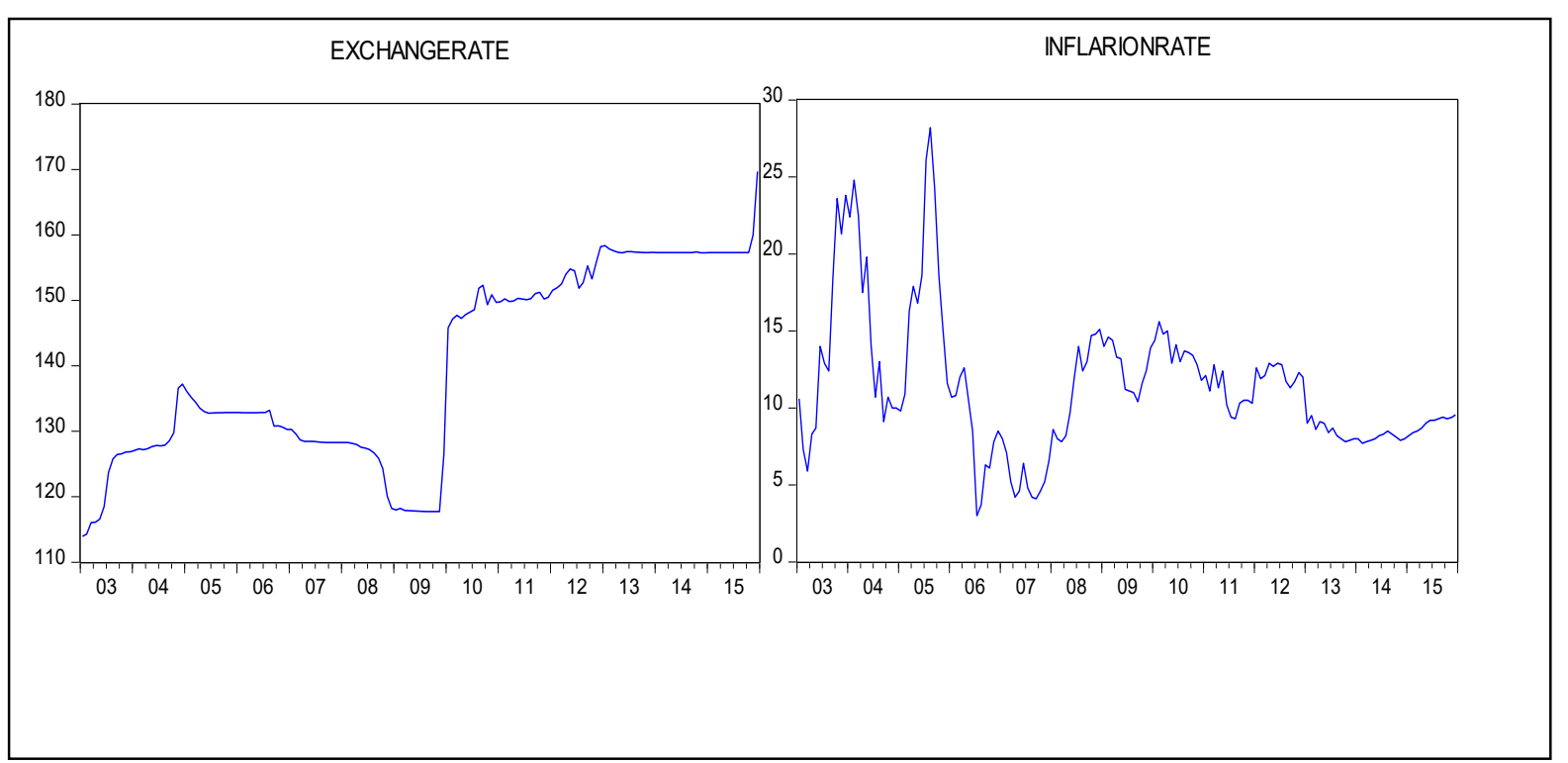

Figure (3) Time plot of Exchange Rate Figure (4) Time plot of the Inflation Rate 
VAR Residuals

DEXCHANGE Residuals

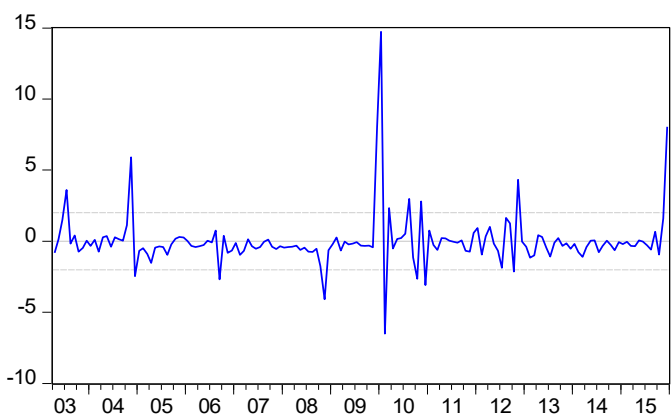

DEXPORT Residuals

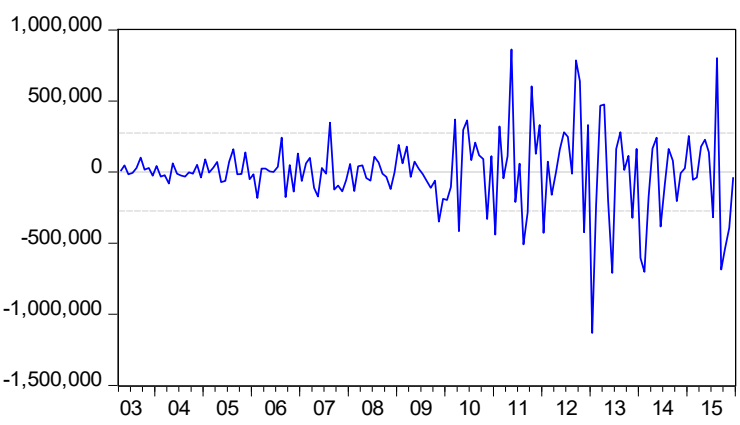

DINFLATION Residuals

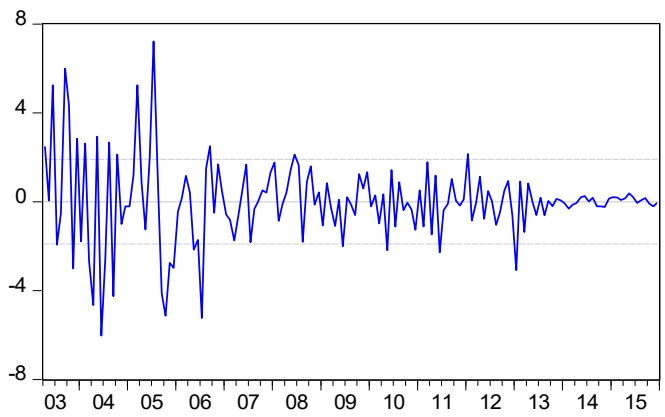

DIMPORT Residuals

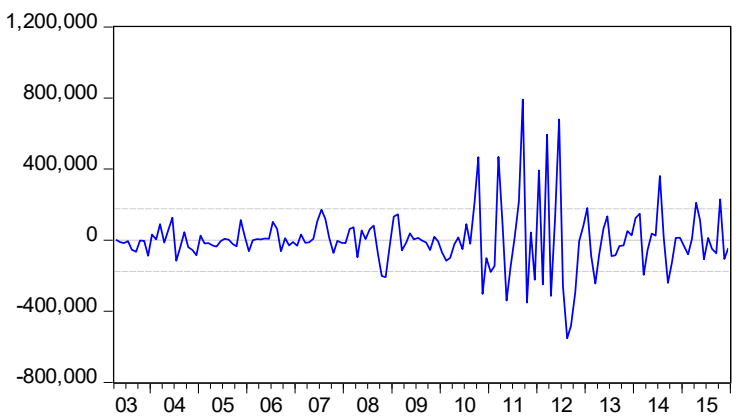

Figure (5) Residuals Time Plot of all Variables

\subsection{Stationarity Test}

Table (1.0) represents the Stationarity test at the original series and first differences, constant, linear trend and probability values in brackets. The probability values (p-values) at a level is greater than $0.05^{\prime}$ In some of the variable except inflation rate. The result showed the existence of unit root. Since the series is Non-stationary series and produces spurious regression, there is a need for the first difference of order I(1). The p-value for all the variables at the order I(1) was tested for stationarity respectively and the series was stationary. 
Table 4.1: Stationarity Test Using Unit Roots Test

\begin{tabular}{|c|c|c|c|c|c|}
\hline Variable & Levels & & Lag 1 & & Co-Integration \\
\hline & Constant & $\begin{array}{l}\text { Constant, } \\
\text { linear trend }\end{array}$ & Constant & \multicolumn{2}{|l|}{$\begin{array}{l}\text { Constant } \\
\text { linear trend }\end{array}$} \\
\hline Exchange rate $\left(E X C_{t}\right.$ & $-0.8949(0.787)$ & $-2.2994(0.4314)$ & $-7.4183(0.000)$ & $-7.3836(0.00)$ & $\mathrm{I}(1)$ \\
\hline Inflation rate $\left(I N F_{t}\right)$ & $\begin{array}{l}-3.1706 \\
(0.0237)\end{array}$ & $-3.5996(0.033)$ & $-10.7179(0.00)$ & $-10.7536(0.00$ & $\mathrm{I}(1)$ \\
\hline $\operatorname{Import}\left(I M P_{t}\right)$ & $-2.6847(0.079)$ & $-4.444(0.0025)$ & $-28.7258(0.000)$ & $-28.6312(0.00)$ & $\mathrm{I}(1)$ \\
\hline Export $\left(E X P_{t}\right)$ & $-2.416(0.1388)$ & $-3.7902(0.019)$ & $-7.4183(0.000)$ & $-7.3836(0.00)$ & $\mathrm{I}(1)$ \\
\hline $\begin{array}{l}\% \text { level } \\
5 \% \text { level } \\
10 \% \text { level }\end{array}$ & $\begin{array}{l}-3.4731 \\
-2.8802 \\
-2.5768\end{array}$ & $\begin{array}{l}-4.0187 \\
-3.144 \\
.3 .1454\end{array}$ & & & \\
\hline
\end{tabular}

\subsection{Vector Autoregressive models Lag Criteria}

The best lag length (p) is selected to minimize the information criteria. The commonly used information criteria are the Akaike information criterion, Hannau-Quinn information criterion and Schwarz information criterion (SIC).

Table (4.2 Result of VAR Lag Information Criteria

\begin{tabular}{ccccccc}
\hline \hline Lag & LogL & LR & FPE & AIC & SC & HQ \\
\hline \hline 0 & -4990.379 & NA & $3.81 \mathrm{e}+24$ & 67.95073 & 68.03210 & 67.98379 \\
1 & -4648.602 & 660.3042 & $4.53 \mathrm{e}+22$ & 63.51839 & $63.92525^{*}$ & 63.68370 \\
2 & -4622.739 & $48.55867^{*}$ & $3.96 \mathrm{e}+22^{*}$ & $63.38420^{*}$ & 64.11655 & $63.68176^{*}$ \\
3 & -4616.688 & 11.03083 & $4.54 \mathrm{e}+22$ & 63.51957 & 64.57741 & 63.94938 \\
4 & -4603.285 & 23.70621 & $4.71 \mathrm{e}+22$ & 63.55490 & 64.93823 & 64.11696 \\
5 & -4593.872 & 16.13741 & $5.18 \mathrm{e}+22$ & 63.64451 & 65.35333 & 64.33882 \\
6 & -4585.677 & 13.60203 & $5.79 \mathrm{e}+22$ & 63.75071 & 65.78502 & 64.57727 \\
7 & -4577.260 & 13.51351 & $6.47 \mathrm{e}+22$ & 63.85387 & 66.21367 & 64.81268 \\
8 & -4561.376 & 24.63540 & $6.54 \mathrm{e}+22$ & 63.85546 & 66.54075 & 64.94652 \\
\hline \hline
\end{tabular}

The table above reveals that the lag of order one $(\mathrm{p}=1)$ is adequate for the model based on the Schwarz information criterion (SIC). The best lag length (p) is the lag that minimizes the information criteria. 


\subsection{Model Estimation}

The vector autoregressive model is fitted using the lag selection criteria which indicate lag one and the model is written as following in matrix form

$$
\begin{aligned}
& \left(\begin{array}{l}
E X C_{t} \\
I N F_{t} \\
I M P_{t} \\
E X P_{t}
\end{array}\right)=\left(\begin{array}{l}
C_{1} \\
C_{2} \\
C_{3} \\
C_{4}
\end{array}\right)+\left(\begin{array}{llll}
\gamma_{11} & \gamma_{12} & \gamma_{13} & \gamma_{14} \\
\gamma_{21} & \gamma_{22} & \gamma_{23} & \gamma_{24} \\
\gamma_{31} & \gamma_{32} & \gamma_{33} & \gamma_{34} \\
\gamma_{41} & \gamma_{42} & \gamma_{43} & \gamma_{44}
\end{array}\right)\left(\begin{array}{l}
E X C_{t-1} \\
I N F_{t-1} \\
I M P_{t-1} \\
E X P_{t-1}
\end{array}\right)+\left(\begin{array}{c}
\varepsilon_{1} \\
\varepsilon_{2} \\
\varepsilon_{3} \\
\varepsilon \varepsilon_{4}
\end{array}\right) \\
& \left(\begin{array}{l}
E X C_{t} \\
I N F_{t} \\
E X P_{t} \\
I M P_{t}
\end{array}\right)=\left(\begin{array}{l}
0.244 \\
0.0032 \\
5746.5 \\
3303.8
\end{array}\right)+\left(\begin{array}{cccc}
0.41 & 0.085 & -8.7 \times 10^{-7} & -3.6 \times 10^{-7} \\
0.047 & 0.144 & -8.2 \times 10^{-8} & -3.3 \times 10^{-7} \\
8450 & -5689.2 & -0.447 & 0.084 \\
9047.9 & 141.6 & 0.0267 & -0.678
\end{array}\right)\left(\begin{array}{l}
E X C_{t-1} \\
I N F_{t-1} \\
E X P_{t-1} \\
I M P_{t-1}
\end{array}\right)
\end{aligned}
$$

$0)$

$\boldsymbol{E X}_{\boldsymbol{t}}=0.408566000533 * \boldsymbol{E} \boldsymbol{X} \boldsymbol{C}_{\boldsymbol{t}-\mathbf{1}}+0.0850388461236 * \mathbf{I N F}_{\mathrm{t}-\mathbf{1}}-8.72349414531 \mathrm{e}-$ $07 * \mathbf{E X P}_{\mathbf{t}-\mathbf{1}}-3.58032564495 \mathrm{e}-07 * \mathbf{I} \mathbf{M P}_{\mathrm{t}-\mathbf{1}}+0.24424072832$

$\mathbf{I N} F_{t}=0.0470808331981 * \boldsymbol{E} \boldsymbol{X} \boldsymbol{C}_{\boldsymbol{t}-\mathbf{1}}+0.144045339116 * \mathbf{I N F}_{\mathbf{t}-\mathbf{1}}-8.15848642746 \mathrm{e}-08 * \mathbf{E X P}_{\mathbf{t}-\mathbf{1}}$ - 3.30413948155e-07*IMPP $\mathbf{t - 1}+0.00323088672268$

(5.4)

$\mathbf{E X P}_{\mathbf{t}-\mathbf{1}}=8450.31308839 * \boldsymbol{E X} \boldsymbol{C}_{\boldsymbol{t}-\mathbf{1}}-5689.22800003 * \mathbf{I N F}_{\mathbf{t}-\mathbf{1}}-0.44745755935 * \mathbf{E X P}_{\mathbf{t}-\mathbf{1}}+$ $0.0842974105976 * \mathbf{I M} \mathbf{P}_{\mathbf{t}-\mathbf{1}}+5146.52715592$

$\mathbf{I M P}_{\mathbf{t}}=9047.8476478 * \boldsymbol{E} \boldsymbol{X} \boldsymbol{C}_{\boldsymbol{t}-\mathbf{1}}+1401.64012243 * \mathbf{I N F}_{\mathbf{t}-\mathbf{1}}+0.0267067105562 * \mathbf{E X P}_{\mathbf{t}-\mathbf{1}}-$ $0.678470180283 * \mathbf{I M P} \mathbf{P}_{t-1}+3303.7910264$

\subsection{Stability}

The vector autoregressive model was tested for stability using the roots of the characteristic polynomial with the variables of EXC, INF, EXP and IMP, the result is presented in table (4.3) and figure (6). The result below satisfies the stability condition as no value of the variable lie inside the unit root circle and the absolute value of the characteristic polynomial is less than one. Since all the roots lie inside the unit root circle, then the vector autoregressive model satisfies the stability condition, indicating that all the models are stable. 
Table (4.3) Root of the characteristic polynomial

\begin{tabular}{cc}
\hline \hline Root & Modulus \\
\hline \hline-0.686934 & 0.686934 \\
-0.426685 & 0.426685 \\
0.410868 & 0.410868 \\
0.129435 & 0.129435 \\
\hline \hline
\end{tabular}

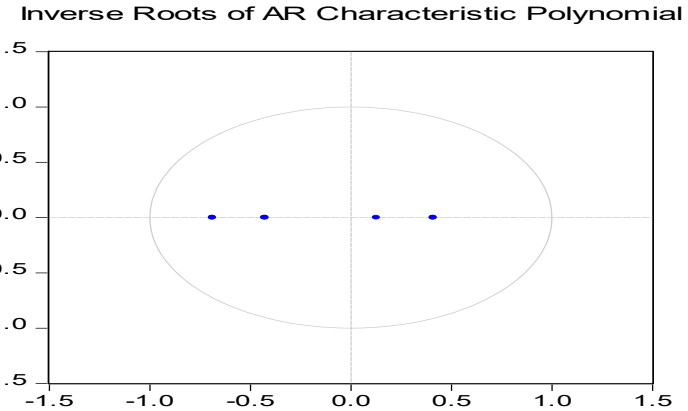

Figure 6 inverse root of the characteristic polynomial

\subsection{Co-Integration Test}

Table (4.4) Johanson Cointegration Test

\begin{tabular}{|c|c|c|c|c|c|c|}
\hline & & & 0.05 & & Max- & 0.05 \\
\hline Hypothesized & Eigenvalue & Trace & Critical & Prob. & Eigen & $\begin{array}{l}\text { Critical } \\
\text { value }\end{array}$ \\
\hline No. of CE(s) & & Statistic & value & & statistic & \\
\hline None & 0.460026 & 230.59 & 47.856 & 0.000 & 93.6674 & 27.5843 \\
\hline At most 1 & 0.37497 & 136.919 & 29.7971 & 0.000 & 71.4335 & 21.7316 \\
\hline At most 2 & 0.22907 & 65.487 & 15.4947 & 0.000 & 39.543 & 14.2646 \\
\hline At most 3 & 0.15691 & 25.9498 & 3.8415 & 0.000 & 25.944 & 3.84146 \\
\hline
\end{tabular}

Johanson co-integration test in the table (4.4) containing: Eigenvalue, trace test, critical value at $0.05 \%$, probability value, maximum Eigenvalue and the critical value corresponding to max Eigenvalue. Disclosed that all the four variables are co-integrated with eigenvalues and trace test greater than the critical value at 0.05levelof significance representing a long-run association among the variables (Johansen, 1988).

Table (4.5) Granger Causality Test Result

\begin{tabular}{|l|l|l|l|l|l|}
\hline \multirow{2}{*}{$\begin{array}{l}\text { Dependent } \\
\text { Variable }\end{array}$} & \multicolumn{4}{|c|}{ Independent Variable } \\
\cline { 2 - 6 } & EXC & INF & IMP & EXP & ALL \\
\hline EXC $_{t}$ & $\mathbf{2 9 . 3 9 9 ( 0 . 0 0 0 )}$ & $1.426(0.490)$ & $0.0889(0.96)$ & $3.602(0.165)$ & $4.9148(0.555)$ \\
\hline $\mathrm{INF}_{\mathrm{t}}$ & $0.331(0.84)$ & $3.872(0.423)$ & $0.91(0.1876)$ & $0.88(0.245)$ & $0.877(0.989)$ \\
\hline $\mathrm{IMP}_{\mathrm{t}}$ & $2.204(0.33)$ & $0.611(0.736)$ & $\mathbf{4 2 . 8 7 5 ( 0 . 0 0 )}$ & $2.291(0.318)$ & $5.3135(0.504)$ \\
\hline $\mathrm{EXP}_{\mathrm{t}}$ & $0.61(0.977)$ & $0.364(0.833)$ & $\mathbf{8 . 0 8 8}(\mathbf{0 . 0 1 7 5})$ & $\mathbf{1 3 8 . 6 2 4 ( 0 . 0 0 )}$ & $9.6316(0.14)$ \\
\hline
\end{tabular}

Granger causality test (see table 4.5), reveals that causality among the variables is unidirectional. For the test on the exchange rate is significantly caused the exchange rate (chisquare $=29.399, \mathrm{pv}=0.00<0.05$ ) The joint effect of the exchange rate do not granger cause 
inflation rate import and export. Inflation rate do not granger cause inflation rate, exchange rate, export and import but their chi-square value are significant. Similarly import is significantly cause import (chi-square $=42.875$, $\mathrm{p}$-value $=0.000<0.05$ ). the joint effect do not granger cause exchange rate, inflation rate and export. Finally, export was found to significantly cause export and Granger cause import (chi-square $=8.088$, p-value $=$ $0.0175<0.05$ ), and do not granger cause exchange rate and inflation rate.

\subsection{Impulse Response}

The impulse response is used to identify the direction of the dynamic behaviour among the variables and also used to assess the extent of shock on each variable in the study. In appendix (1), The first row represents the response of the exchange rate to shock to itself and all other variables. The exchange rate had an immediate and positive shock to the exchange rate and did not have an instant and positive answer to all other variables. The response of inflation rate to itself and exchange rate, import and export are shown in the second row. Inflation had a positive response to itself and a negative response to all other variables. The response of export to itself and all other variables are in row 3 the export response to export is positive and failing throughout the period but not zero. Export had a negative response to shock on all the remaining variables. The last row represents the import response to shock to itself and all other variables.
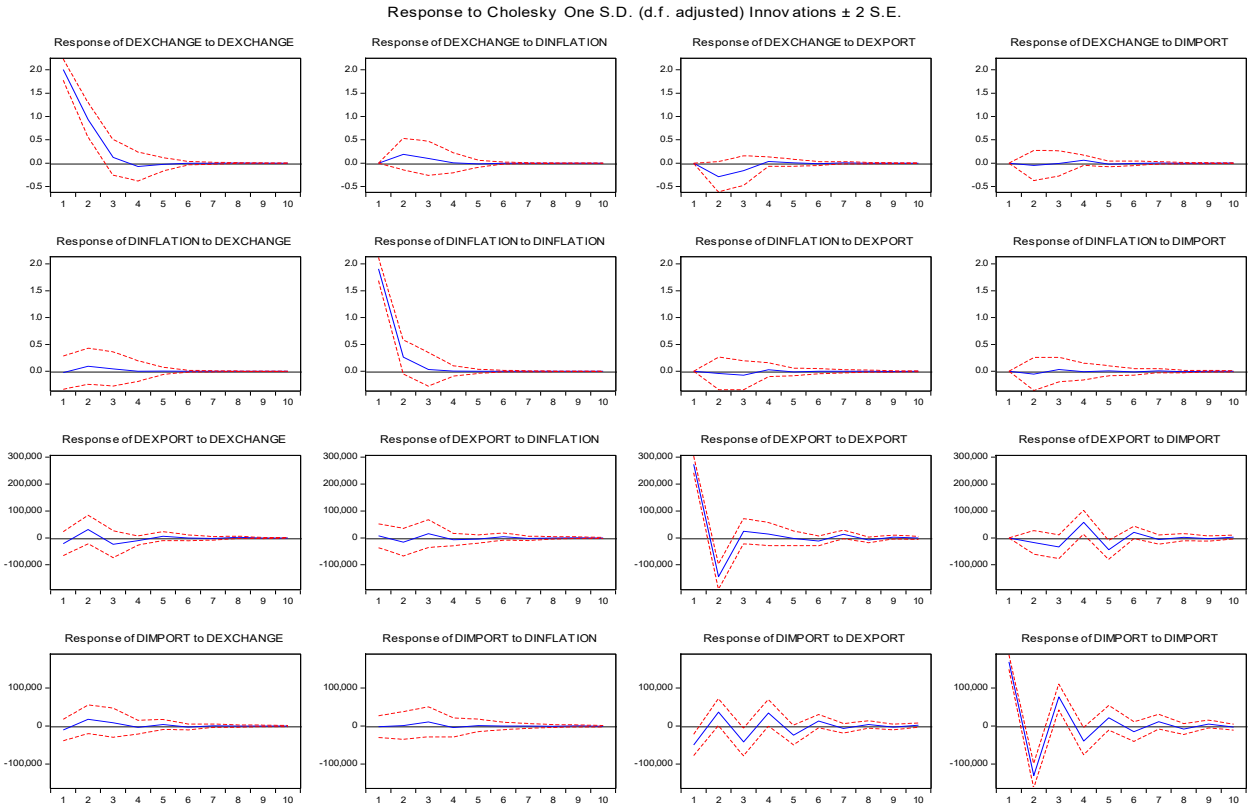


\section{VARIANCE DECOMPOSITION}

\subsection{Variance Decomposition Of Exchange Rate}

The variance decomposition shows that in the short run and long run exchange rate response are $(100 \%$ and $90 \%)$ of the error forecast variance. While in the short exchange rate response $(0.00 \%)$ to all other variables and the long run $(72 \%, 107 \%$ and $4.5 \%)$ to the error forecast of the variance to the rest variables.

\subsection{Variance Decomposition Of Inflation Rate}

The variance decomposition of inflation rate in response to the short run and long run is (99.9\% and $99.6 \%)$ respectively. While $(1.7 \%)$ for the exchange rate and $(0.00 \%)$ for import and export in the short run. In the long-run inflation rate response to the shock of the exchange rate, export and import are $(25.8 \%, 4.2 \%$ and $68.9 \%)$ of the error variance forecast.

\subsection{Variance Decomposition Of Export}

The responses of export due to the short run and long run are (99\% and 98\%) of the error variance of the forecast. While the response due to short-run of export on the exchange rate, inflation rate and import are $(60 \%, 96 \%$ and $0.0 \%)$ and in the long run is $(144 \%, 32 \%$ and $80 \%)$ respectively.

\subsection{Variance Decomposition Of Import}

The response of import due to the short run and long run is (92\% and 91\%) respectively. While the response due to shock of import to all other variables in the shock run is $(36 \%, 1 \%$ and $794 \%)$ and due to long run are $(87 \%, 1 \%$ and $765 \%)$ forecast error of variances.

\section{CONCLUSION}

The inter-relationship between exchange rate, inflation rate, exports and imports was stable at cointegration of order I(1), In the long run, all the variable in the study was cointegrated at 0.05 level using max-eigenvalues and the trace test. The grager causality test between export and import was significant and unidirectional for export and import only, while the joint effect of other variable does not Granger cause each other. However, the impulse response is used to identify the direction of the dynamic behaviour among the variables and also used to assess the extent of shock on each variable in the study, while all the variable have positive shock to their self and negative shock each other. This study recommends that the Exportation of goods should be improved through the purchase of improved technology and means of manufacture; this will further decrease the request for the importation of goods.

\section{REFERENCE}

[1] Bderezak. A.A \& Samet(2016) the relationship between exchange rate and inflation: An Empirical Study of Turkey. International Journal of Economics \& Financial Issues 6(4)

[2] Brooks, C. (2008). Introductory econometrics for finance. New York: Cambridge University Press

[3] Box, G.E.P. \& Jenkins, G.M. (1976). Time series analysis: Forecasting and control, HoldenDay, San Francisco.

[4] Chatfield, C. (1984). The Analysis of Time Series, Chapman and Hall publisher. 
[5] CENTRAL Bank of Nigeria (2017). Statistical Bulletin, http;/www.centralbank.org

[6] Etuk, E. H. and Bartholomew. U. (2012). Forecasting Nigerian inflation rates by a seasonal ARIMA model. Sendra Academic Publishers Burnaby, British Columbia Canadian 6(3)2180.

[7] Enders W. (1995). Applied econometric time series. New York: John Wiley \& Sons.

[8] Gujarati, D.N (2013). Basic Econometrics. McGraw Hills: Glasgow.

[9] Granger, C. (1987). Some Properties of Time Series Data and Their Use in Econometric Model specification. Journal of Econometrics, 16, 121-130

[10] Lutkepol H. (2003) Vector autoregressive models. Companion to theoretical econometrics;

[11] Johansen, S, (1988). Statistical Analysis of Co-integration Vectors. Journal of Economic Dynamics and Control, 12, 231-254.

[12] Johansen, S., \& Juselius, K. (1990). Maximum likelihood Estimation and Inference on Cointegration-with the Application to the Demand for Money, Oxford Bulletin of Economics and Statistics, 52,169-210.

[13] Jarita. D. (2008). Impact of exchange rate shock on prices of Import and Exports.www.researchgate.net

[14] Oluyemi and Essi (2017). The effect of the Exchange rate, Import and Export in Nigeria from January 1996 to June 2015. International Journal Of Economics and Business Management 3(66-77)

[15] Sims, C. (2003). Macro-economic and reality. The Econometrics (48) 1-48

[16] Tuaneh, Godwin Lebari.(2018) Vector autoregressive modelling of the interaction among macroeconomic stability indicators in Nigeria. Asian Journal of Economics, Business and Accounting.9 (4)

[17] Tuaneh. G. B. and Wiri. L (2019). Unrestricted Vector Autoregressive Modelling of the Interaction among Oil Prices, Exchange Rate and Inflation in Nigeria. Asian Journal of Probability and Statistics. 2(4)

[18] Ukwuoma H (2019). The Effect of ICT on Economic Growth in Nigeria. International Journal of Management, Technology and Engineering

[19] Wiri. L and Essi. I.D.(2018). Seasonal Autoregressive Integrated Moving Average (SARIMA) modelling and forecasting of Inflation Rate in Nigerian. International Journal of Applied Science and Mathematical Theory 4(1)

[20] Wiri, L. and Tuaneh. G. B, (2019). Modelling Nigeria Crude Oil Prices Using ARIMA, PreIntervention and Post- Intervention model. Asian Journal of Probability and Statistics. 3(1) 